\title{
Occurrence of endocrine-disrupting chemicals in indoor dust
}

\author{
Hyun-Min Hwang ${ }^{a}{ }^{*}$, Eun-Kee Park ${ }^{b}, 1$, Thomas M. Young ${ }^{a}$, and Bruce D. Hammock ${ }^{b}$ \\ aDepartment of Civil and Environmental Engineering, University of California, One Shields Ave., \\ Davis, CA 95616, USA \\ bDepartment of Entomology and Cancer Research Center, University of California, One Shields \\ Avenue, Davis, CA 95616, USA
}

\section{Abstract}

Human exposure to indoor dust enriched with endocrine-disrupting chemicals released from numerous indoor sources has been a focus of increasing concern. Longer residence times and elevated contaminant concentrations in the indoor environment may increase chances of exposure to these contaminants by 1000 -fold compared to outdoor exposure. To investigate the occurrence of semi-volatile endocrine-disrupting chemicals, including PBDEs (polybrominated diphenyl ethers), PCBs (polychlorinated biphenyls), phthalates, pyrethroids, DDT (dichlorodiphenyltrichloroethane) and its metabolites, and chlordanes, indoor dust samples were collected from household vacuum cleaner bags provided by 10 apartments and 1 community hall in Davis, California, USA. Chemical analyses show that all indoor dust samples are highly contaminated by target analytes measured in the present study. Di-(2-ethylhexyl)phthalate was the most abundant (104-7630 $\mu \mathrm{g} / \mathrm{g})$ in all samples and higher than other target analytes by 2 to 6 orders of magnitude. PBDEs were also found at high concentrations (1780-25,200 ng/g). Although the use of PCBs has been banned or restricted for decades, some samples had PCBs at levels that are considered to be concerns for human health, indicating that the potential risk posed by PCBs still remains high in the indoor environment, probably due to a lack of dissipation processes and continuous release from the sources. Although the use of some PBDEs is being phased out in some parts of the U.S., this trend may apply to PBDEs as well. We can anticipate that exposure to PBDEs will continue as long as the general public keeps using existing household items such as sofas, mattresses, and carpets that contain PBDEs. This study provides additional information that indoor dust is highly contaminated by persistent and endocrine-disrupting chemicals.

\section{Keywords}

Indoor dust; Endocrine-disrupting chemicals; PBDEs; PCBs; Insecticides; Phthalates

\section{Introduction}

Many studies have shown that the indoor environment can be a significant source of exposure to some contaminants especially for younger children because of their behavioral factors and longer indoor residence time (Paustenbach et al., 1997; Lioy et al., 2002; Butte, 2004; Roberts and Ott, 2007). Most of these studies have focused on lead, volatile organic compounds, pesticides, and tobacco smoke and less attention has been paid to potential health risks of exposure to persistent and semi-volatile endocrine-disrupting chemicals

\footnotetext{
*Corresponding author. Tel.: +1 530752 1755; fax: +1 530752 7872. hmhwang@ucdavis.edu (H.-M. Hwang).

${ }^{1}$ Current address: Research and Education Unit, Dust Diseases Board, Level 14, 82 Elizabeth Street, Sydney, NSW 2000, Australia.
} 
(EDCs) such as polychlorinated biphenyls (PCBs), polybrominated diphenyl ethers (PBDEs), and phthalates in the indoor environment. It has been suggested that indoor dust is highly contaminated by these EDCs and many other toxic chemicals and thus indoor residential exposure may be a greater contributor to overall exposure than diet especially for children (Butte and Heinzow, 2002; Lioy et al., 2002; Rudel et al., 2003; Wilford et al., 2005; Roberts and Ott, 2007; Lorber, 2008).

Epidemiological studies have demonstrated that some cases of adverse health effects such as childhood leukemia, neurological disorders, non-Hodgkin's lymphoma, and respiratory symptoms were strongly associated with indoor contaminants (Bornehag et al., 2004; Butte, 2004; Colt et al., 2005). Potential risk of exposure of younger children to some toxic chemicals through ingestion of contaminated dust might be equal to or more significant than exposure through food consumption. Toddlers and younger children may especially be at greater risk because of a combination of physiological and behavioral factors such as small body mass, less ability to detoxify and excrete xenobiotic toxic chemicals, rapid growth, development and differentiation of their vital organ systems, activities close to the floor, tendency for inadvertent ingestion of non-food items, and hand-to-mouth behavior (Cantalamessa, 1993; Stanek et al., 1998; Landrigan et al., 1999; Butte and Heinzow, 2002; Roberts and Ott, 2007). More exposure of younger children to contaminated indoor dust may be responsible for the higher levels of contaminants in their blood. Fischer et al. (2006) found that levels of PBDEs in children's blood were 2- to 5-fold higher than those of their parents and, accordingly, suggested that children may face higher risks of adverse health effects. Dietary uptake of PBDEs was not different between children and their parents. In case of adults, ingestion of contaminated dust is much less important exposure pathway than dietary uptake.

Longer residence times and elevated contaminant concentrations in the indoor environment may increase chance of exposure to contaminants by 1000 -fold compared to outdoor exposures (Smith, 1988). Most people spend nearly 90\% of their time indoors (Hubal et al., 2000; CalEPA, 2004) so there are much higher opportunities for people to be exposed to contaminants in the indoor environment than in the outdoor environment. Levels of contaminants such as phthalates, PBDEs, and PCBs in indoor air and dust are often higher than outdoor levels. Butt et al. (2004) reported that PBDEs on indoor window surfaces were 1.5 to 20 times higher than on outdoor window surfaces. Wilson et al. (2001) found that PCBs in floor dust from child daycare centers were three orders of magnitude higher than outdoor soil levels.

Numerous household products, building materials, and pest control activities are known as major sources of EDCs. Household products such as appliances, furniture, carpet pads, and mattresses contain substantial amounts of flame retardants such as PBDEs. Polyurethane foam used in sofas and mattresses may contain PBDEs up to $30 \%$ by weight (WHO, 1994). Joint sealing materials such as rubbery caulking that were used until the late 1970s or possibly the early 1980 s contained PCBs up to $300 \mathrm{mg} / \mathrm{g}$ (Herrick et al., 2004; Kohler et al., 2005). Carpet backing materials, vinyl floor, shoes, children's toys, and many other household products contain considerable amounts of phthalates (ATSDR, 2002). Therefore, the dust emanating from mattresses, carpet, and furniture contains high levels of hazardous compounds such as PBDEs and phthalates. Off-gassed contaminants from many indoor sources may be adsorbed on and accumulate in the dust. Direct application, release from some household products (e.g., pest-proof wool carpet, wood), and track-in by people and pets from outside also can contribute to indoor contamination by pesticides.

Indoor dust is a fine heterogeneous mixture of organic and inorganic materials composed of animal fibers, pollen, clay, fungi, as well as particulate matter emanating from carpet and 
furniture (Lioy et al., 2002). Indoor dust behaves as a repository and a concentrator of many organic contaminants and thus levels of contaminants in indoor dust can be used as a proxy to assess the exposure potential to contaminants in the indoor environment. Typically, carpeted surfaces are the largest reservoir of indoor dust. Organic pollutants bound to dust are more persistent indoors due to a lack of biotic (e.g., microbial) and abiotic (e.g., photolysis) degradation and other dissipation processes (e.g., volatilization, dissolution) and consequently they have a greater exposure potential.

Evidence for the adverse effects of EDCs on human health is mounting (Crisp et al., 1998; NRC, 1999; Rasier et al., 2006). Traditionally, consumption of food has been considered a primary route of exposure to contaminants like those measured in the present study. However, it is becoming clear that exposure through ingestion and/or inhalation of indoor dust may be comparable to corresponding food consumption especially for younger children (Lioy et al., 2002; Wilford et al., 2005). Thus, there is the need to collect more information about the occurrence of EDCs in indoor dust and the associated potential risk. To date, only a limited number of studies have investigated multiple classes of EDCs in indoor dust. Most studies rather have focused on a single class of chemicals such as PBDEs, PCBs, or pesticides. The present study investigated the occurrence of multiple EDCs (PBDEs, PCBs, phthalates, pyrethroids, DDT (dichlorodiphenyltrichloroethane) and its metabolites, and chlordanes) in indoor dust. The magnitude and variability of the levels of potentially toxic chemicals in indoor dust then can be interpreted as a proxy for the severity and variability of exposures and possible health risks of these compounds.

\section{Materials and methods}

\subsection{Sample collection}

To measure persistent endocrine-disrupting chemicals, used household vacuum cleaner bags were obtained from 10 apartments and 1 community hall located in Davis, California, USA in fall of 2004. Makes and models of vacuum cleaners and bags were not identified. Construction years of apartments were not identified. The apartments and the community hall where samples were collected all had carpeted floors. Dust from each bag was sieved with a $100 \mu \mathrm{m}$ metal screen and stored in glass jars (pre-cleaned with hexane) at $-20{ }^{\circ} \mathrm{C}$ until chemical analysis was performed. Dust smaller than vacuum cleaner bag pore size likely escaped capture during operation of the vacuum cleaners. Particle size of the dust analyzed for the present study was therefore larger than the unknown vacuum cleaner bag pore size and smaller than $100 \mu \mathrm{m}$.

\subsection{Chemical analyses}

Indoor dust samples were analyzed for chlordanes, DDTs, pyrethroids, phthalates, PCBs, and PBDEs (Table 1). Analytical procedures were slightly modified from Hwang et al. (2006). An aliquot ( $4 \mathrm{~g}$ ) of dust was extracted with dichloromethane using a Soxhlet extraction apparatus for $8 \mathrm{~h}$. Before extraction, surrogate standards (PCB 103, $\mathrm{d}_{10^{-}}$ permethrin) were added to all samples for the evaluation of the method performance. The extracts were concentrated to $2 \mathrm{~mL}$ of hexane and were subjected to alumina column chromatography to remove interferences. Alumina was combusted at $450{ }^{\circ} \mathrm{C}$ for $4 \mathrm{~h}$ and stored in the oven at $130{ }^{\circ} \mathrm{C}$. Prior to use, alumina was deactivated ( $4 \%$ by weight) with purified water. The columns were conditioned with pentane and sample extracts were loaded. Then, the columns were eluted with dichloromethane: pentane (1:1) mixture. The eluted solvents were concentrated to $1 \mathrm{~mL}$ of hexane and the internal standard (PCB 140) was added. Target compounds were analyzed with Agilent 6890 gas chromatograph equipped with a J\&W DB-5MS fused silica capillary column (30 m×0.25 mm ID, $0.25 \mu \mathrm{m}$ film thickness) and an Agilent 5973 mass spectrometer. The mass spectrometer was 
operated in electron impact $(70 \mathrm{eV})$ and selected ion monitoring (SIM) mode. GC oven temperature for PBDEs, pyrethroids, and phthalates started at $60{ }^{\circ} \mathrm{C}$ and ramped to $150{ }^{\circ} \mathrm{C}$ at $15^{\circ} \mathrm{C} / \mathrm{min}, 220{ }^{\circ} \mathrm{C}$ at $5^{\circ} \mathrm{C} / \mathrm{min}, 310^{\circ} \mathrm{C}$ at $7{ }^{\circ} \mathrm{C} / \mathrm{min}$, and maintained for $11 \mathrm{~min}$. Oven temperature for $\mathrm{PCBs}$ and $\mathrm{OC}$ pesticides started at $80^{\circ} \mathrm{C}$ and ramped to $170{ }^{\circ} \mathrm{C}$ at $12{ }^{\circ} \mathrm{C} /$ $\min , 210^{\circ} \mathrm{C}$ at $1{ }^{\circ} \mathrm{C} / \mathrm{min}, 300^{\circ} \mathrm{C}$ at $20^{\circ} \mathrm{C} / \mathrm{min}$, and maintained for $8 \mathrm{~min}$. Method detection limits of all target compounds (except phthalates) ranged from 3 to $10 \mathrm{ng} / \mathrm{g}$. To measure PBDEs and phthalates, sample extracts were diluted prior to GC analyses. Concentrations of all phthalates in the laboratory blank samples were around 100-200 ng/g. Blank concentrations of phthalates were not subtracted from sample concentrations because the levels of phthalates in dust samples were higher than blank levels by several orders of magnitude. To validate analytical procedures and ensure data quality, a procedural blank, sample duplicate, and standard reference material (NIST SRM 1941a, marine sediment) were also analyzed. Relative percent differences for duplicate samples were less than $20 \%$. The levels of PCBs in the SRM were within $\pm 20 \%$ of certified values. Moisture content of the dust was not measured.

\section{Results and discussion}

Concentrations of EDCs in indoor dust samples were highly variable (Table 2) and did not show any meaningful correlation with each other. Chlordane, pyrethroid insecticides, PBDEs, and phthalates were found above method detection limits in all samples. Di-(2ethylhexyl) phthalate (DEHP) was detected at the highest concentrations in all samples and was generally higher than other contaminants by 2 to 6 orders of magnitude. Levels of $p, p^{\prime}-$ DDT and $p, p^{\prime}$-DDD (dichlorodiphenyldichlroethane) were lower than method detection limits or non-detectable (ND) in all samples and levels of $p, p^{\prime}$-DDE (dichlorodiphenyldichloroethylene), which is a metabolite of $p, p^{\prime}$-DDT, were very low (ND$18.2 \mathrm{ng} / \mathrm{g}$ ). Concentrations of EDCs in indoor dust reported by others are summarized in Table 3 for comparison. It needs to be noted that some studies, including the present study, fractionated samples by size of dust with sieving before chemical analysis while some other studies (Bornehag et al., 2004;Julien et al., 2008) analyzed samples without sieving.

According to Lewis et al. (1999) and Paustenbach et al. (1997), PAHs and pesticides are more enriched in the smaller size of indoor dust. This trend of enrichment in finer dust is likely to be the same for other semi-volatile organic contaminants like PCBs and PBDEs that are physico-chemically similar to PAHs. Generally, contaminants bound to smaller particles are more bioavailable and the pulmonary residence time is longer (Paustenbach et al., 1997).

\subsection{Insecticides}

Measurable levels of chlordanes and pyrethroids were found in all apartment samples, indicating that insecticides were applied in or around all these apartments. In the U.S., residential indoor and outdoor application of insecticides is widespread. A survey of 513 homes in 4 metropolitan areas (Detroit, Iowa, Los Angeles, Seattle) showed that $94.3 \%$ had treated in or nearby their homes for insect control (Colt et al., 2004). Telephone interviews of 238 homes in Missouri showed that $97.8 \%$ used pesticides at least once per year and more than two thirds used pesticides five times or more per year (Davis et al., 1992). Whyatt et al. (2007) reported that among 620 inner-city mothers from New York City, 87\% used some forms of pest control even during pregnancy and $46 \%$ used higher-toxicity methods (e.g., can spray, pest bomb). Typically, direct application is the primary source of insecticides indoors while release from some household products (e.g., pest-proof wool carpet, wood), track-in by people and pets, and drift-in by wind from outside also can contribute to indoor contamination (Butte, 2004). Lu et al. (2006) found a positive correlation between the levels of pyrethroid metabolites in the urine of elementary school-age children and the use of 
pyrethroids by their parents for insect control for floors, beds, and gardens. Colt et al (2006) found a significant trend of increased risk of non-Hodgkin's lymphoma with increasing levels of $c i s$-chlordane residues in house dust. Therefore the levels of insecticides in indoor dust can represent a potential exposure risk for residents to these insecticides.

It is interesting to note that measurable levels of chlordanes (cis- and trans-chlordanes plus cis- and trans-nonachlors) were found in all samples although the use of technical chlordane for termite control was phased out decades ago. Technical chlordane, which is a mixture of more than 100 different compounds, was used as an insecticide in the US from 1948 to 1988 (ATSDR, 1994). Because of its persistence in the environment, potential cancer risk, and other critical adverse biological effects observed in wildlife and humans (ATSDR, 1994), the use of technical chlordane for all purposes except for termite control and non-food crops was prohibited in 1978. All above-ground application on non-food crops was also banned in 1983, but use as a termiticide for underground application around the foundation of homes and buildings was continued until 1988 when the use of chlordane was suspended for all purposes in the U.S. (USEPA, 1988). The U.S. EPA (IRIS) classified chlordane as group B2 (probable human carcinogen).

Concentrations of total chlordanes in all apartment samples were relatively constant, ranging from 11.6 to $131 \mathrm{ng} / \mathrm{g}$ with a median of $20.7 \mathrm{ng} / \mathrm{g}$. The sample collected from the community hall contained a very high level of total chlordanes $(1540 \mathrm{ng} / \mathrm{g})$. This high level of residue suggests that the community hall applied chlordanes extensively. Other studies found chlordanes in indoor dust at much higher levels than the present study (Table 3). Rudel et al. (2003) found high levels of cis-chlordane ( $<300-9970 \mathrm{ng} / \mathrm{g}$, with a mean of 328 $\mathrm{ng} / \mathrm{g})$ and trans-chlordane $(<300-10,600 \mathrm{ng} / \mathrm{g}$, with a mean of $383 \mathrm{ng} / \mathrm{g})$ in indoor dust. The results of the present and other studies are good examples showing that persistent pollutants like chlordanes can affect human health even long after their use has been prohibited.

Degradation half-life of chlordanes in soil is over 20 years (Mattina et al., 1999). Considering that household use of chlordanes was only for outdoor application for termite control, chlordanes detected in indoor dust presumably were tracked-in by humans and pets and/or drifted-in by wind.

Pyrethroids are synthetic analogues of pyrethrins, which are naturally occurring insecticides isolated from pyrethrum flowers. Structurally modified pyrethroids are highly lipophilic, more photostable, so they last longer in the environment, and often more toxic to insects, resulting in more effective insecticides than pyrethrins (Casida, 1980). Pyrethroids are active ingredients of many insect control products (e.g., spray, powder, mosquito coil, electroevaporator paper, treated wood) intended for indoor use. Although pyrethroids are known to be extremely toxic to fish and bees, they are much less toxic for mammals. However, recent studies provide evidence that high exposure to pyrethroids may cause cancers (Tisch et al., 2002; Choi et al., 2004; Gabbianelli et al., 2004) and potential endocrine disruption in humans (Go et al., 1999). These effects were reported at levels that were regarded as safe.

Among the 5 pyrethroids measured, permethrin (cis- plus trans-) and cypermethrin were found most frequently and at the highest concentrations. Permethrin and cypermethrin varied from ND to $3030 \mathrm{ng} / \mathrm{g}$ and ND to $4360 \mathrm{ng} / \mathrm{g}$, respectively. In all samples, transpermethrin was always higher than cis-permethrin. Lambda-cyhalothrin was found in 5 out of 11 samples and esfenvalerate and cyfluthrin were not detected or were lower than MDL $(10 \mathrm{ng} / \mathrm{g})$ in all samples. Concentrations of permethrin measured in the present study are much lower than those found in other areas of the U.S. and Germany (Table 3). BergerPreiss et al. (2002) found very high levels of permethrin (mean: 53,700 ng/g, 90th percentile: $129,100 \mathrm{ng} / \mathrm{g}$ ) in house dust $(<2 \mathrm{~mm})$ collected from homes having permethrin treated woolen textile floor coverings. 
Occurrence patterns and levels of insecticides in indoor dust may mirror the amounts and types of insecticides applied by residents and the market share of active ingredients included in insecticide products that can be purchased from local stores. The results of local retail store surveys match the observed pyrethroid occurrence patterns in the present and other studies. Surveys of local retail stores revealed that $80 \%$ of insecticides sold for household application contain one or more pyrethroids (unpublished data) as active ingredients. All $(n=17)$ spray and fogger products for indoor use contain at least one pyrethroid at levels 0.035 to $12.6 \%$ by volume. Garden care products such as insect-free fertilizers also contain pyrethroids. These products contain permethrin and cypermethrin more frequently at much higher levels than other pyrethroids. One fumigating fogger contains $12.6 \%$ of permethrin. Permethrin is added as a mixture of cis- and trans-isomers and the cis- and trans-isomer fraction is generally around 30 and $70 \%$, respectively. This matches with the results found in the present and other studies (Table 3 ). Only one of the 34 products found in the survey for indoor use contained esfenvalerate and no product had cyfluthrin. The lack of significant home use in this region could be a plausible explanation for the failure to find esfenvalerate or cyfluthrin.

The levels of pyrethroids in indoor dust from the apartments were higher than chlordanes by up to two orders of magnitude (Table 2). Similar trends also were reported by others (Mukerjee et al., 1997;Lewis et al., 1999;Colt et al., 2004;Rudel et al., 2003). Presumably because pyrethroids are currently the most prevalent household insecticides for both indoor and outdoor applications, while technical chlordane was banned for all uses about 20 years ago. After the recent ban on the use of some organophosphorus insecticides such as chlorpyrifos for non-agricultural applications, sales of insecticides containing pyrethroids for residential and non-residential (e.g., school, park) applications have increased sharply and currently pyrethroids dominate the household insecticide market. According to U.S. EPA usage data, approximately 1 million $\mathrm{kg}$ of permethrin are applied annually to agricultural, residential, structural, and public health sites. About 0.7 million $\mathrm{kg}$ is used on non-agricultural sites and $41 \%$ of it is applied by homeowners on residential areas (USEPA, 2006).

The levels of pyrethroids measured in the present and other studies demonstrate that the indoor environment is highly contaminated and probably require actions to reduce the possibility of adverse health impacts. In the U.S., pyrethroids are among the most frequently detected contaminants in humans. A national survey conducted by the Centers for Disease Control (CDC, 2005) found metabolites of pyrethroids in more than 50\% of the test population. Due to a lack of sunlight and moisture, photodegradation, hydrolysis, and microbial degradation are limited inside the house and thus pyrethroids applied indoors can persist more than a year. Leng et al (2005) detected about $20 \%$ of the initially applied permethrin a year after application. This persistence coupled with repeated applications of insecticides indoors increases the exposure and health risk.

\subsection{Polychlorinated biphenyls (PCBs)}

Though manufacturing of PCBs was banned in the U.S. in 1977, PCBs are still of concern for human health and the environment due to their persistence and continuous release from various sources that are currently in use. PCBs are recognized as developmental neurotoxins and also associated with effects on immune, reproductive, and endocrine systems (ATSDR, 2000). Extended periods of exposure to PCBs can also provoke cancers (ATSDR, 2000). Colt et al. (2005) found an association between the increased risk of non-Hodgkin lymphoma and exposure to PCBs in carpet dust. The U.S. EPA (IRIS) categorized PCBs as probable human carcinogens (Group B2). Historically consumption of contaminated food such as fish, meats, and dairy products has been a major concern for human exposure to PCBs and major sources have been tracked to releases from closed systems such as 
electrical transformers and capacitors or accidental spills. Only recently, PCBs in hidden sources like building materials (e.g., joint sealant) that can contaminate the indoor environment have received more attention.

PCBs are very stable with environmental half-lives of 10 to 20 years (Erickson, 1997). Inside buildings, where dissipation is extremely slow due to lack of moisture, sunlight, and microbial activity, PCBs are likely to persist much longer and, accordingly, pose health risk for an extended period. PCBs measured in dust from the apartment samples ranged from $<10$ to $227 \mathrm{ng} / \mathrm{g}$. One sample had PCBs at a level higher than U.S. EPA risk-based guideline (USEPA, 2004) for residential soil (220 ng/g). Three samples had PCBs exceeding the California screening level $(89 \mathrm{ng} / \mathrm{g})$ set for residential soil (CalEPA, 2005). PCB concentration in dust from the community hall was $570 \mathrm{ng} / \mathrm{g}$, which is lower than EPA riskbased guideline (USEPA, 2004) for commercial land soil (740 ng/g) but higher than the California screening level $(300 \mathrm{ng} / \mathrm{g}$ ) for commercial land soil (CalEPA, 2005) by a factor of 1.9 , indicating the presence of possible health risk. This high level of PCBs found in the community hall sample indicates that buildings of this community hall may still have PCBimpregnated building materials that were used when this community hall was constructed in the 1950s and/or refurbished in the late 1970s. Congener patterns found in the community hall sample do not match any single Aroclor, suggesting that building materials contain two or more Aroclors. Levels of PCBs found in the present study are much lower than those found in indoor dust from other areas of the U.S. (Table 3). Wilson et al. (2001) found high levels of PCBs (sum of 20 PCBs) in floor dust from child day care centers, ranging from 120 to $3150 \mathrm{ng} / \mathrm{g}$ that are two to three orders of magnitude higher than outdoor soil levels.

Rudel et al. (2003) reported that PCBs 52, 103, and 153 in house dust were found at levels as high as $50,000 \mathrm{ng} / \mathrm{g}$.

PCBs were added to some building materials such as joint sealant (e.g., rubbery caulking), paint, and plaster to improve their effectiveness and endurance (ATSDR, 2000). Some joint sealants, paints, and plasters manufactured between the 1940s and the late 1970s contained very high levels of PCBs. Kohler et al (2005) reported high levels of PCBs in joint sealants, exceeding $10,000 \mu \mathrm{g} / \mathrm{g}$ and $100,000 \mu \mathrm{g} / \mathrm{g}$ in $21 \%$ and $9.6 \%$ of samples. Caulking materials collected from schools and public buildings in the Boston area contained elevated levels of PCBs up to 33,000 $\mu \mathrm{g} / \mathrm{g}$ (Herrick et al., 2004). Plasters collected in the Bergen area of Norway contained PCBs ranging from non-detected to $290 \mu \mathrm{g} / \mathrm{g}$ (Andersson et al., 2004). Release of PCBs from these building materials can significantly contaminate indoor air and dust. The primary transport pathway of PCBs in building materials to indoor dust is volatilization from these source materials and subsequent adsorption on dust and/or scaling of these building materials. Therefore, houses constructed/refurbished with PCB-imbedded building materials are likely to have high levels of PCBs in indoor air and dust. Generally, age of the houses is a good determinant of PCB levels in indoor dust (Andersson et al., 2004; Colt et al., 2005; Kohler et al., 2005). Colt et al. (2005) found the highest concentrations in houses built before 1970 and the lowest in houses built after 1980 .

\subsection{Polybrominated diphenyl ethers (PBDEs)}

To reduce fire-related injury and death and to minimize property damage, PBDEs have been incorporated as flame retardants into many household products such as TVs, computer cases, and polyurethane forms used in sofas, mattresses, chairs, and carpet pads. These products contain PBDEs at levels ranging from 5 to $30 \%$ by mass (WHO, 1994). PentaBDEs (PBDEs 47, 99, 100) are mainly used for polyurethane forms, furniture, carpet pads, and car seat covers, while deca-BDE (PBDE 209) is usually used for hard plastic such as computer cases and TVs. PBDEs can be released from these household products and significantly contaminate the indoor environment. Small particles emanating from PBDE 
containing household products especially sofas, mattresses, chairs, and carpet pads can increase PBDE levels in dust. Volatilized low molecular weight PBDEs from these products can be also bound to dust and accumulate indoors.

The present study detected high levels of PBDEs in indoor dust. The sum of 7 congeners (PBDEs 47, 66, 99, 100, 138, 153, 154) in apartment dust samples varied from 1780 to $25,200 \mathrm{ng} / \mathrm{g}$ with a median of $9020 \mathrm{ng} / \mathrm{g}$. Congener patterns of PBDEs in all samples measured in the present study were similar, and PBDEs 47 and 99 were the most abundant (Fig. 1). These two congeners accounted for about $80 \%$ of the total PBDEs. Generally levels of dust-bound PBDEs measured in the present and other studies are much higher compared to other environmental media such as soil, sediment, and fish (Sharp and Lunder, 2004).

As shown in Fig. 1, congener patterns of PBDEs in indoor dust are similar to the pattern of the commercial penta-BDE mixture. In commercial penta-BDE mixture, PBDE 47 to PBDE 99 ratio is about 0.6 (Stapleton et al., 2005). The ratios found in the present study varied from 0.37 to 0.87 . The levels of penta-BDEs $(47+99+100)$ detected in the present study are similar to those found in other areas of the U.S. (Rudel et al., 2003;Stapleton et al., 2005; Schecter et al., 2005) and Canada (Wilford et al., 2005) but much higher than other areas such as Kuwait (Gevao et al., 2006) and European countries (Santillo et al., 2003). Reported PBDE levels in indoor dust show that penta $(47+99+100)$ to deca $(209)$ ratios in Canada and US samples are much higher ranging from 0.51 to 1.3 compared to those found in other countries ( 0.02 to 0.33 ). Higher levels of penta-BDEs in house dust collected in the U.S. and Canada are because household products used in these countries contain higher levels of penta-BDEs. The U.S., as a number one PBDE consumer, accounts for 95, 40, and $45 \%$ of the total world consumption of penta-, octa-, and deca-BDEs, respectively (BSEF, 2000). Penta-BDEs are also more easily released from the products because penta-BDEs are added to soft products such as sofas and chairs that are extremely susceptible to wear and tear through frequent contact with humans. The general public in Canada and U.S. is therefore facing greater health risks from exposure to penta-BDEs, which are more bioavailable than heavier congeners like deca-BDE. Current total PBDE residues in blood and mother's milk in the U.S. population are the highest reported worldwide to date (Schecter et al., 2003;Hites, 2004). It is likely that the U.S. population is exposed through sources such as food and dust containing higher levels of PBDEs (Schecter et al., 2004). Many studies reported that ingestion of dust is a likely primary exposure route for PBDEs, especially for toddlers and young children (Stapleton et al., 2005;Wilford et al., 2005). Fischer et al. (2006) found that children contained 2- to 5-fold higher levels of PBDEs in blood compared to their parents and PBDE congener profiles in children's serum more closely resembled the profile in house dust, indicating that children are exposed more to PBDEs mainly through inadvertent dust ingestion and consequently are more vulnerable to adverse health effects. Generally dust ingestion is not a primary exposure pathway of these toxic chemicals for adults and it can be explained by PBDE profiles found in human milk and blood that are different from those in house dust (Schecter et al., 2003; Hites, 2004; Fischer et al., 2006). PBDEs in human breast adipose tissue collected from San Francisco Bay women in the late 1990s (She et al., 2002) had a different profile from that in dust (Fig. 1). Estimated exposure scenario indicates that ingestion of house dust may account for $80 \%$ and $14 \%$ of total daily PBDE intake for toddlers and adults, respectively (Wilford et al., 2005).

Though there is no clear evidence of toxic effects of PBDEs on humans, animal studies indicate that PBDEs can cause endocrine disruption, reproductive and developmental toxicity (ATSDR, 2004; Birnbaum and Staskal, 2004). USEPA (IRIS) classified PBDEs as Group D (not classifiable as human carcinogen) and there is no known evidence of PBDE related cancer development. However, like many industrial compounds, the health effects of 
PBDEs are poorly studied. Due to adverse health effects, high bioaccumulation potential, and environmental persistence, the European Union has banned the use of commercial penta- and octa-BDE mixtures. The State of California in the U.S. will phase out these two mixtures by 2008 and some other states in the U.S. are expected to ban their use in the near future (Sharp and Lunder, 2004). One penta-BDE manufacturer (Great Lakes Chemical Co.) planned to cease production voluntarily by the end of 2004 (Sharp and Lunder, 2004). However, as observed in the cases of PCBs and chlordanes, the health risk potential of PBDEs is likely to be remain high for an extended period following the phase out of these PBDE mixtures in new products because PBDEs are very stable and will be released continuously from products containing PBDEs as long as their use is continued.

\subsection{Phthalates}

Phthalates were the most abundant contaminants in the present study. Concentrations of di(2-ethylhexyl) phthalate (DEHP; 104-7630 $\mu \mathrm{g} / \mathrm{g}$ ) and butyl benzyl phthalate (50-1290 $\mu \mathrm{g} / \mathrm{g}$ ) were higher than other contaminants by 2 to 6 orders of magnitude. Rudel et al. (2003) also found DEHP in all household dust samples at levels much higher than other organic contaminants (Table 3). Although few studies report phthalates and other contaminants together in indoor dust, this much higher level of phthalates may be commonly observed. Unlike PBDEs that show big differences between North American and other countries, DEHP in indoor dust from the U.S. and European countries falls within a similar range (Table 3).

The ubiquitous occurrence of DEHP and other phthalates at high levels in indoor dust is due to the wide spectrum of sources. Additionally, phthalates are incorporated in polymer mixtures physically rather than chemically, so they can be easily released from these source products into the indoor environment throughout the life of the products. Phthalates have been used extensively as nonreactive plasticizers since the 1930s to increase the flexibility of many rigid polymers, including polyvinyl chloride (PVC). DEHP is the predominant phthalate in soft PVC products, which may contain phthalates approximately up to $40 \%$ by mass. Phthalates are currently added to numerous products such as building materials (e.g., vinyl floor, carpet, plastic wall covering), household products (e.g., shower curtains, electrical cable covering, furniture upholstery, synthetic leather, shoes), personal-care products (e.g., perfumes, lotions, nail polish, cosmetics), food packaging, medical products (e.g., intravenous fluids, blood storage bags, tubing), pharmaceuticals (e.g., coatings), paints, children's toy, electronic devices, and industrial plastics (ATSDR, 2002).

Phthalates were thought to be safe but recent studies revealed that phthalates may cause cancers, endocrine disruption, and reproductive and developmental toxicity (ATSDR, 2002; Hauser and Calafat, 2005). Duty et al. (2003) demonstrated association between exposure to phthalates and DNA damage in human sperm. U.S. EPA (IRIS) classified DEHP and butyl benzyl phthalate as Group B (probable human carcinogen) and Group C (possible human carcinogen), respectively. DEHP is also suspected as an agent that may cause asthma and allergic symptoms in children. Bornehag et al. (2004) and Kolarik et al. (2008) reported associations between exposure to DEHP in indoor dust and asthma and wheezing in children. The levels of DEHP detected in some apartment samples analyzed for the present study are as high as those found in Bornehag et al. (2004), indicating that children who were living in those apartments have been exposed to high levels of phthalates at which adverse health effects can be provoked.

\section{Conclusion}

The present study demonstrates that the indoor environment is significantly contaminated by EDCs and their levels are high enough to be possibly linked to some adverse health effects. 
The results further demonstrate that persistent pollutants like chlordanes and PCBs can affect human health for extended periods even long after their usages were prohibited and/or restricted. Comparing the levels of dust associated EDCs to the guidelines for soil/dust ingestion indicates that public health managers need to pay more attention to ingestion of contaminated dust as an important exposure route especially for toddlers and younger children.

As a preliminary study, dust samples were collected from only 10 apartments. Systematic investigation is required to find possible links between exposure to EDCs indoors and adverse health effects. The results of the present study suggest that frequent floor vacuuming and ventilation of indoor air may be wanted in an attempt to reduce indoor exposure to EDCs. Reduced indoor application of pesticides may also help keep their levels low in the indoor environment. Public education about the sources of EDCs and their health effects will substantially increase the awareness of the risk, and consequently may reduce the incidence of disease. Workers should also be aware of possible risks of exposure to EDCs, for example, when they demolish or renovate buildings having PCB-imbedded materials or remove old carpets containing PBDEs and phthalates.

\section{Acknowledgments}

We would like to thank the residents who provided vacuum cleaner bags from their homes. This research was supported by the National Institute of Environmental Health Sciences Center for Environmental Health Sciences P30 ES05707, the National Institute of Environmental Health Sciences Superfund Basic Research Program P42 ES04699, and Center for Children's Environmental Health and Disease Prevention P01 ES11269. It has not been subjected to a funding agency review and does not necessarily reflect the views of the funding agency.

\section{References}

Al Bitar, F. Hazardous chemicals in Belgian House Dust. Brussel: Greenpeace Belgium; 2004.

Andersson M, Ottensen RT, Volden T. Building materials as a source of PCB pollution in Bergen, Norway. Sci Total Environ 2004;325:139-44. [PubMed: 15144784]

ATSDR. Toxicological profile for chlordane. Atlanta, GA: U.S. Department of Health and Human Services; 1994. Agency for toxic substances and disease registry

ATSDR. Toxicological profile for polychlorinated biphenyls (PCBs). Atlanta, GA: Agency for Toxic Substances and Disease Registry, U.S. Department of Health and Human Services; 2000.

ATSDR. Toxicological profile for di(2-ethylhexyl)phthalate. Atlanta, GA: Agency for Toxic Substances and Disease Registry, U.S. Department of Health and Human Services; 2002.

ATSDR. Toxicological profile for Polybrominated biphenyls and Polybrominated diphenyl ethers. Atlanta, GA: Agency for Toxic Substances and Disease Registry, U.S. Department of Health and Human Services; 2004.

Berger-Preiss E, Levsen K, Leng G, Idel H, Sugiri D, Ranft U. Indoor pyrethroid exposure in homes with woolen textile floor coverings. Int J Hyg Environ Health 2002;205:459-72. [PubMed: 12455268]

Birnbaum LS, Staskal DF. Brominated flame retardants: cause for concern? Environ Health Perspect 2004;112:9-17. [PubMed: 14698924]

Bornehag CG, Sundell J, Weschler CJ, Sigsgaard T, Lundgren B, Hasselgren M, et al. The association between asthma and allergic symptoms in children and phthalates in house dust: a nested casecontrol study. Environ Health Perspect 2004;112:1393-7. [PubMed: 15471731]

Bradman A, Whitaker D, Quiros L, Castorina R, Henn BC, Nishioka M, et al. Pesticides and their metabolites in the homes and urine of farmworker children living in the Salinas Valley, CA. J Exp Sci Environ Epidemiol 2007;17:331-49.

BSEF. (Bromine Science and Environmental Forum). BSEF factsheet: major brominated flame retardants volume estimates. 2000. 
Butt CM, Diamond ML, Truong J, Ikonomou MG, Schure AFH. Spatial distribution of polybrominated diphenyl ethers in southern Ontario as measured in indoor and outdoor window organic films. Environ Sci Technol 2004;38:724-31. [PubMed: 14968856]

Butte W, Heinzow B. Pollutants in house dust as indicators of indoor contamination. Rev Environ Contam Toxicol 2002;175:1-46. [PubMed: 12206053]

Butte, W. The handbook of environmental chemistry. Vol. 4. Berlin: Springer-Verlag; 2004. Sources and impacts of pesticides in indoor environment; p. 89-116.Part $F$

CalEPA. Indoor air pollution in California. Sacramento, CA: Air Resources Board, California Environmental Protection Agency; 2004.

CalEPA. Use of California human health screening levels (CHHSLs) in evaluation of contaminated properties. Sacramento, CA: California Environmental Protection Agency; 2005.

Cantalamessa F. Acute toxicity of two pyrethroids, permethrin and cypermethrin, in neonatal and adult rats. Arch Toxicol 1993;67:510-3. [PubMed: 8240001]

Casida JE. Pyrethrum flowers and pyrethroid insecticides. Environ Health Perspect 1980;34:189-202. [PubMed: 6993201]

Choi SM, Yoo SD, Lee BM. Toxicological characteristics of endocrine-disrupting chemicals: developmental toxicity, carcinogenicity, and mutagenicity. J Toxicol Environ Health Part B 2004;7:1-32.

Clausen PA, Bille RLL, Nilsson T, Hansen V, Svensmark B, Bøwadt S. Simultaneous extraction of di(2-ethylhexyl)phthalate and nonionic surfactants from house dust: concentrations in floor dust from 15 Danish schools. J Chromatogr A 2003;986:179-90. [PubMed: 12597625]

CDC (Centers for Disease Control and Prevention). Third national report on human exposure to environmental chemicals. Atlanta, GA: National Center for Environmental Health, Centers for Disease Control and Prevention; 2005. NCEH Publication No. 05-0570

Colt JS, Lubin J, Camann D, Davis S, Cerhan J, Severson RK, et al. Comparison of pesticide levels in carpet dust and self-reported pest treatment practices in four US sites. J Expo Anal Environ Epidemiol 2004;14:74-83. [PubMed: 14726946]

Colt JS, Severson RK, Lubin J, Rothman N, Camann D, Davis S, et al. Organochlorines in carpet dust and non-Hodgkin lymphoma. Epidemiol 2005;16:516-25.

Colt JS, Davis S, Severson RK, Lynch CF, Cozen W, Camann D, et al. Residential insecticide use and risk of non-Hodgkin's lymphoma. Cancer Epidemiol Biomarkers Prev 2006;15:251-7. [PubMed: 16492912]

Crisp TM, Dlegg ED, Cooper RL, Wood WP, Anderson DG, Baetcke KP, et al. Environmental endocrine disruption: an effect assessment and analysis. Environ Health Perspect 1998;106(Suppl 1):11-56. [PubMed: 9539004]

Davis JR, Brownson RC, Garcia R. Family pesticide use in the home, garden, orchard, and yard. Arch Environ Contam Toxicol 1992;22:260-6. [PubMed: 1616309]

Duty SM, Singh NP, Silva MJ, Barr DB, Brock JW, Ryan L, et al. The relationship between environmental exposures to phthalates and DNA damage in human sperm using the neutral comet assay. Environ Health Perspect 2003;111:1164-9. [PubMed: 12842768]

Erickson, MD. Analytical chemistry of PCBs. 2nd. Boca Raton, FL: CRC Press; 1997.

Fischer D, Hooper K, Athanasiadou M, Athanassiadis I, Bergman A. Children show highest levels of polybrominated diphenyl ethers in a California family of four: a case study. Environ Health Perspect 2006;114:1581-4. [PubMed: 17035146]

Fromme H, Lahrz T, Piloty M, Gebhart H, Oddoy A, Rüden H. Occurrence of phthalates and musk fragrances in indoor air and dust from apartments and kindergartens in Berlin (Germany). Indoor Air 2004;14:188-95. [PubMed: 15104786]

Gabbianelli R, Nasuti C, Falcioni G, Cantalamessa F. Lymphocyte DNS damage in rats exposed to pyrethroids: effect of supplementation with Vitamins E and C. Toxicology 2004;203:17-26. [PubMed: 15363578]

Gevao B, Al-Bahloul M, Al-Ghadban AN, Al-Omair A, Ali L, Zafar J, et al. House dust as a source of human exposure to polybrominated diphenyl ethers in Kuwait. Chemosphere 2006;64:603-8. [PubMed: 16405952] 
Go V, Garey J, Wolff MS, Pogo BGT. Estrogenic potential of certain pyrethroids compounds in the MCF-7 human breast carcinoma cell line. Environ Health Perspect 1999;107:173-7. [PubMed: 10064545]

Hauser R, Calafat AM. Phthalates and human health. Occup Environ Med 2005;62:806-18. [PubMed: 16234408]

Herrick RF, McClean MD, Meeker JD, Baxter LK, Weymouth GA. An unrecognized source of PCB contamination in schools and other buildings. Environ Health Perspect 2004;112:1051-3. [PubMed: 15238275]

Hites RA. Polybrominated diphenyl ethers in the environment and in people: a meta-analysis of concentrations. Environ Sci Technol 2004;38:945-56. [PubMed: 14998004]

Hubal EAC, Sheldon LS, Burke JM, McCurdy TR, Berry MR, Rigas ML, et al. Children's exposure assessment: a review of factors influencing children's exposure, and the data available to characterize and assess that exposure. Environ Health Perspect 2000;108:475-86.

Hwang HM, Green PG, Young TM. Tidal salt marsh sediment in California, USA. Part 1: Occurrence and sources of organic contaminants. Chemosphere 2006;64:1383-92. [PubMed: 16442586]

United States Environmental Protection Agency. IRIS. Integrated Risk Information System. Washington, DC: cfpub.epa.gov/ncea/iris/index.cfm

Julien R, Adamkiewicz G, Levy JI, Bennett D, Nishioka M, Spengler JD. Pesticide loadings of select organophosphate and pyrethroid pesticides in urban public housing. J Expo Sci Environ Epidemiol 2008;18:167-74. [PubMed: 17495869]

Kohler M, Tremp J, Zennegg M, Seiler C, Minder-Kohler S, Beck M, et al. Joint sealants: an overlooked diffuse source of polychlorinated biphenyls in buildings. Environ Sci Technol 2005;39:1967-73. [PubMed: 15871225]

Kolarik B, Naydenov K, Larsson M, Bornehag CG, Sundell J. The association between phthalates in dust and allergic diseases among Bulgarian children. Environ Health Perspect 2008;116:98-103. [PubMed: 18197306]

Landrigan PJ, Claudio L, Markowitz SB, Berkowitz GS, Brenner BL, Romero H, et al. Pesticides and inner-city children: exposures, risks, and prevention. Environ Health Perspect 1999;107(suppl): 431-7. [PubMed: 10346991]

Leng G, Berger-Preiss E, Levsen K, Ranft U, Sugiri D, Hadnagy W, et al. Pyrethroids used indoorambient monitoring of pyrethroids following a pest control operation. Int J Hyg Environ Health 2005;208:193-9. [PubMed: 15971858]

Lewis RG, Fortune CR, Willis RD, Camann DE, Antley JT. Distribution of pesticides and polycyclic aromatic hydrocarbons in house dust as a function of particle size. Environ Health Perspect 1999;107:721-6. [PubMed: 10464072]

Lioy PJ, Freeman NCG, Millette JR. Dust: a metric for use in residential and building exposure assessment and source characterization. Environ Health Perspect 2002;110:969-83. [PubMed: 12361921]

Lorber M. Exposure of Americans to polybrominated diphenyl ethers. J Expo Sci Environ Epidemiol 2008;18:2-19. [PubMed: 17426733]

Lu C, Barr DB, Pearson M, Bartell S, Bravo R. A longitudinal approach to assessing urban and suburban children's exposure to pyrethroid pesticides. Environ Health Perspect 2006;114:1419-23. [PubMed: 16966099]

Mattina MJI, Iannucci-Berger W, Dykas L, Pardus J. Impact of long-term weathering, mobility, and land use on chlordane residues in soil. Environ Sci Technol 1999;33:2425-31.

Mukerjee S, Ellerson WD, Lewis RG, Stevens RK, Somerville MC, Shadwick DS, et al. An environmental scoping study in the lower Rio Grande Valley of Texas - III. Residential microenvironmental monitoring for air, house dust, and soil. Environ Int 1997;23:657-73.

NRC. Hormonally active agents in the environment. Washington, DC: National Research Council, National Academy Press; 1999.

Øie L, Hersoug LG, Madsen JØ. Residential exposure to plasticizers and its possible role in the pathogenesis of asthma. Environ Health Perspect 1997;105:972-8. [PubMed: 9374082]

Paustenbach DJ, Finley BL, Long TF. The critical role of house dust in understanding the hazards posed by contaminated soils. Int J Toxicol 1997;16:339-62. 
Rasier G, Toppari J, Parent AS, Bourguignon JP. Female sexual maturation and reproduction after prepubertal exposure to estrogens and endocrine disrupting chemicals: a review of rodent and human data. Mol Cell Endocrinol 2006;254-255:187-201.

Roberts JW, Dickey P. Exposure of children to pollutants in house dust and indoor air. Rev Environ Contam Toxicol 1995;143:59-78. [PubMed: 7501867]

Roberts, JW.; Ott, WR. Exposure to pollutants from house dust. In: Ott, WR.; Steinemann, AC.; Wallace, LA., editors. Exposure analysis. Boca Raton, FL: CRC Press; 2007. p. 319-46.

Rudel RA, Camann DE, Spengler JD, Korn LR, Brody JG. Phthalates, alkylphenols, pesticides, polybrominated diphenyl ethers, and other endocrine-disrupting compounds in indoor air and dust. Environ Sci Technol 2003;37:4543-5453. [PubMed: 14594359]

Santillo, D.; Labunska, I.; Fairley, M.; Johnston, P. Greenpeace Research Laboratories Technical Note, GRL-TN-02-2003. Greenpeace Research Laboratories; Exeter, UK: 2003. Consuming chemicals \#2: Hazardous chemicals in house dusts as indicators of chemical exposure in the home.

Schecter A, Pavuk M, Päpke O, Ryan JJ, Birnbaum L, Rosen R. Polybrominated diphenyl ethers (PBDEs) in U S mothers' milk. Environ Health Perspect 2003;111:1723-9. [PubMed: 14594622]

Schecter A, Päpke O, Joseph JE, Tung KC, Staskal D, Birnbaum L. Polybrominated diphenyl ethers contamination of United States food. Environ Sci Technol 2004;38:5306-11. [PubMed: 15543730]

Schecter A, Päpke O, Joseph JE, Tung KC. Polybrominated diphenyl ethers (PBDEs) in U S computers and domestic carper vacuuming: possible sources of human exposure. J Toxicol Environ Health A 2005;68:501-13. [PubMed: 15805045]

Seifert B, Becker K, Helm D, Krause C, Schulz C, Seiwert M. The German environmental survey 1990/1992 (GerES II): reference concentrations of selected environmental pollutants in blood, urine, hair, house dust, drinking water and indoor air. J Expo Anal Environ Epidemiol 2000;10:552-65. [PubMed: 11140439]

Sharp, R.; Lunder, S. Washington, DC: Environmental Working Group; 2004. In the dust: toxic fire retardants in American homes. www.ewg.org/reports/inthedust

She J, Petreas M, Winkler J, Visita P, McKinney M, Kopec D. PBDEs in the San Francisco Bay area: measurements in harbor seal blubber and human breast adipose tissue. Chemosphere 2002;46:697707. [PubMed: 11999793]

Smith K. Air pollution: assessing total exposure in the United States. Environ 1988;30:10-38.

Stanek EJ III, Calabrese EJ, Mundt K, Pekow P, Yeatts KB. Prevalence of soil mouthing/ingestion among healthy children aged 1 to 6. J Soil Contam 1998;7:227-42.

Stapleton HM, Dodder NG, Offenberg JH, Schantz MM, Wise SA. Polybrominated diphenyl ethers in house dust and clothes dryer lint. Environ Sci Technol 2005;39:925-31. [PubMed: 15773463]

Tisch M, Schmezer P, Faulde M, Groh A, Maier H. Genotoxicity studies on permethrin, DEET, and diazinon in primary human nasal mucosal cells. Eur Arch Otorhinolaryngol 2002;259:150-3. [PubMed: 12003267]

USEPA. Federal Register. Vol. 53. Washington, DC: United States Environmental Protection Agency; 1988. p. 11798-805.

USEPA. United States Environmental Protection Agency; 2004. EPA Region 9 Preliminary remediation goals. www.epa.gov/region09/waste/sfund/prg/index.html

USEPA. EPA 738-R-06-017. Washington, DC: United States Environmental Protection Agency; 2006. Registration eligibility decision for permethrin.

Vorhees DJ, Cullen AC, Altshul LM. Polychlorinated biphenyls in house dust and yard soil near a Superfund site. Environ Sci Technol 1999;33:2151-6.

WHO. Environmental Health Criteria. Vol. 162. Geneva: World Health Organization; 1994. Brominated diphenyl ethers.

Wilford BH, Shoeib M, Harner T, Zhu J, Jones KC. Polybrominated diphenyl ethers in indoor dust in Ottawa, Canada: implications for sources and exposure. Environ Sci Technol 2005;39:7027-35. [PubMed: 16201626]

Wilson NK, Chuang JC, Lyu C. Levels of persistent organic pollutants in several child day care centers. J Expo Anal Environ Epidemiol 2001;11:449-58. [PubMed: 11791162] 
Whyatt RM, Garfinkel R, Hoepner LA, Holmes D, Borjas M, Williams MK, et al. Within- and between-home variability in indoor-air insecticide levels during pregnancy among an inner-city cohort from New York City. Environ Health Perspect 2007;115:383-9. [PubMed: 17431487] 


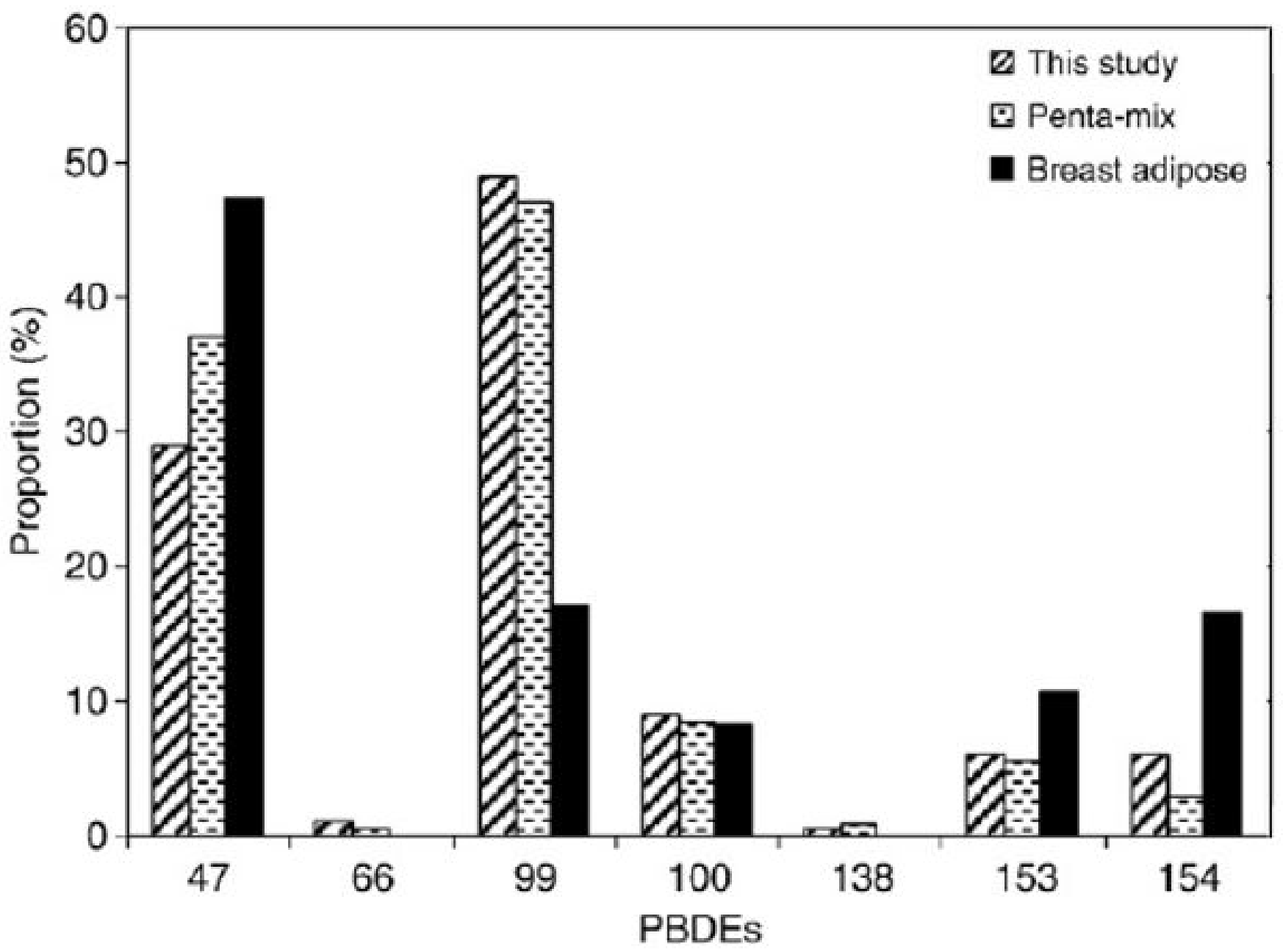

Fig. 1. PBDE congener profile found in the present study and its comparison to profiles in commercial penta-BDE mixture and human breast adipose tissue (She et al., 2002) 
Table 1

\section{Endocrine-disrupting chemicals measured in the present study}

\begin{tabular}{|lll|}
\hline Chlorinated pesticides & Phthalates & Pyrethroids \\
\hline$p, p^{\prime}$-DDE & Dimethyl phthalate & Lambda-cyhalothrin \\
$p, p^{\prime}$-DDD & Diethyl phthalate & cis-Permethrin \\
$p, p^{\prime}$-DDT & Dibutyl phthalate & trans-Permethrin \\
cis-chlordane & Butylbenzyl phthalate & Cyfluthrin \\
trans-chlordane & Bis(2-ethylhexyl) phthalate & Cypermethrin \\
cis-nonachlor & & Esfenvalerate \\
trans-nonachlor & & \\
Polybrominated diphenyl ethers & & Polychlorinated biphenyls \\
\hline $47,66,99,100,138,153,154$ & $8 / 5,18,20 / 33,28,31,44,49,52,56 / 60,70,74 / 71,80 / 66,87 / 115,95,97,99,101 / 90,105,110,114,118$, \\
& $128,138 / 160,141,149,151,153,156,157,158,167,174,177,180,183,187,189,190 / 170,194,195$, \\
\hline
\end{tabular}




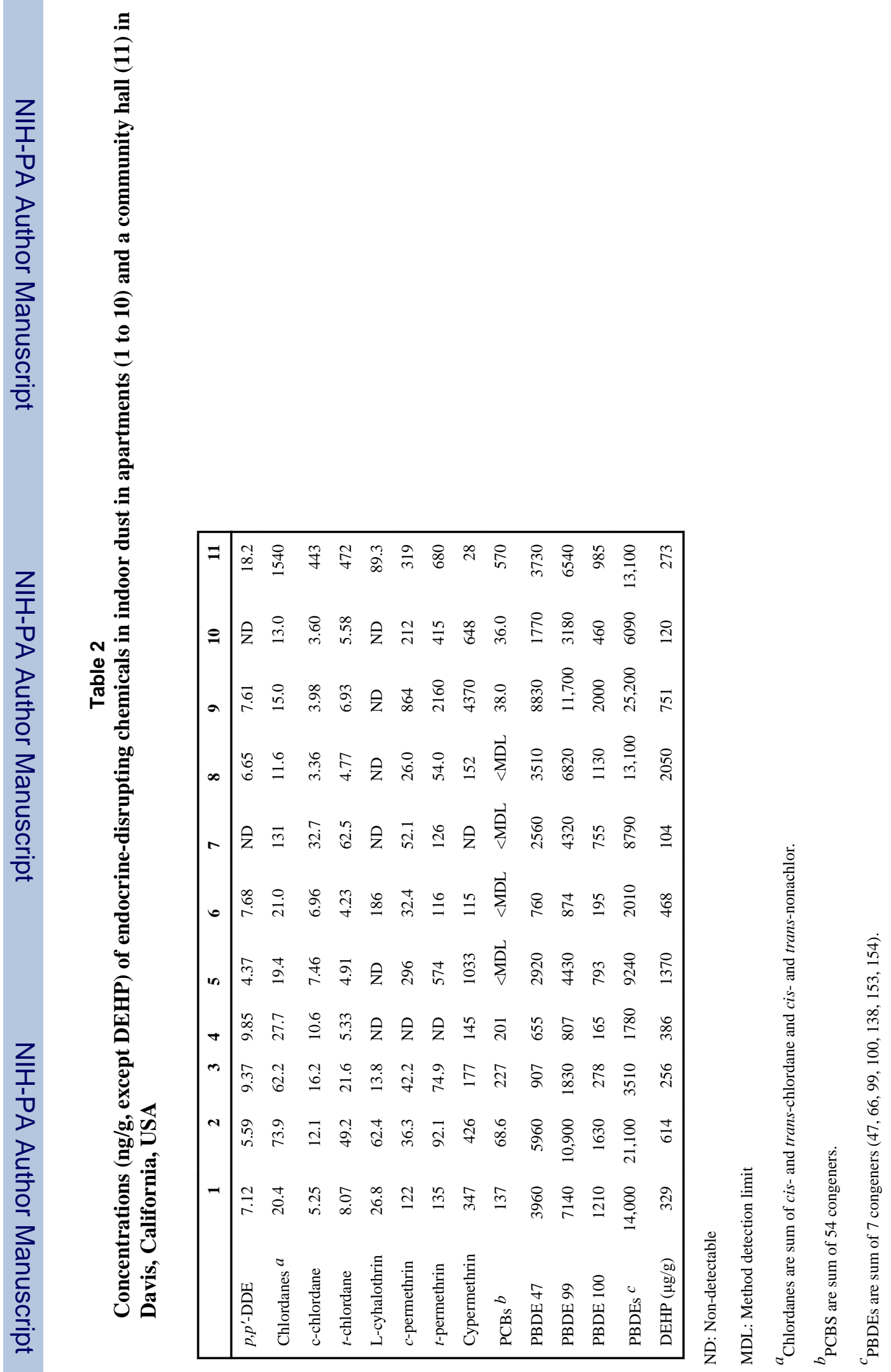




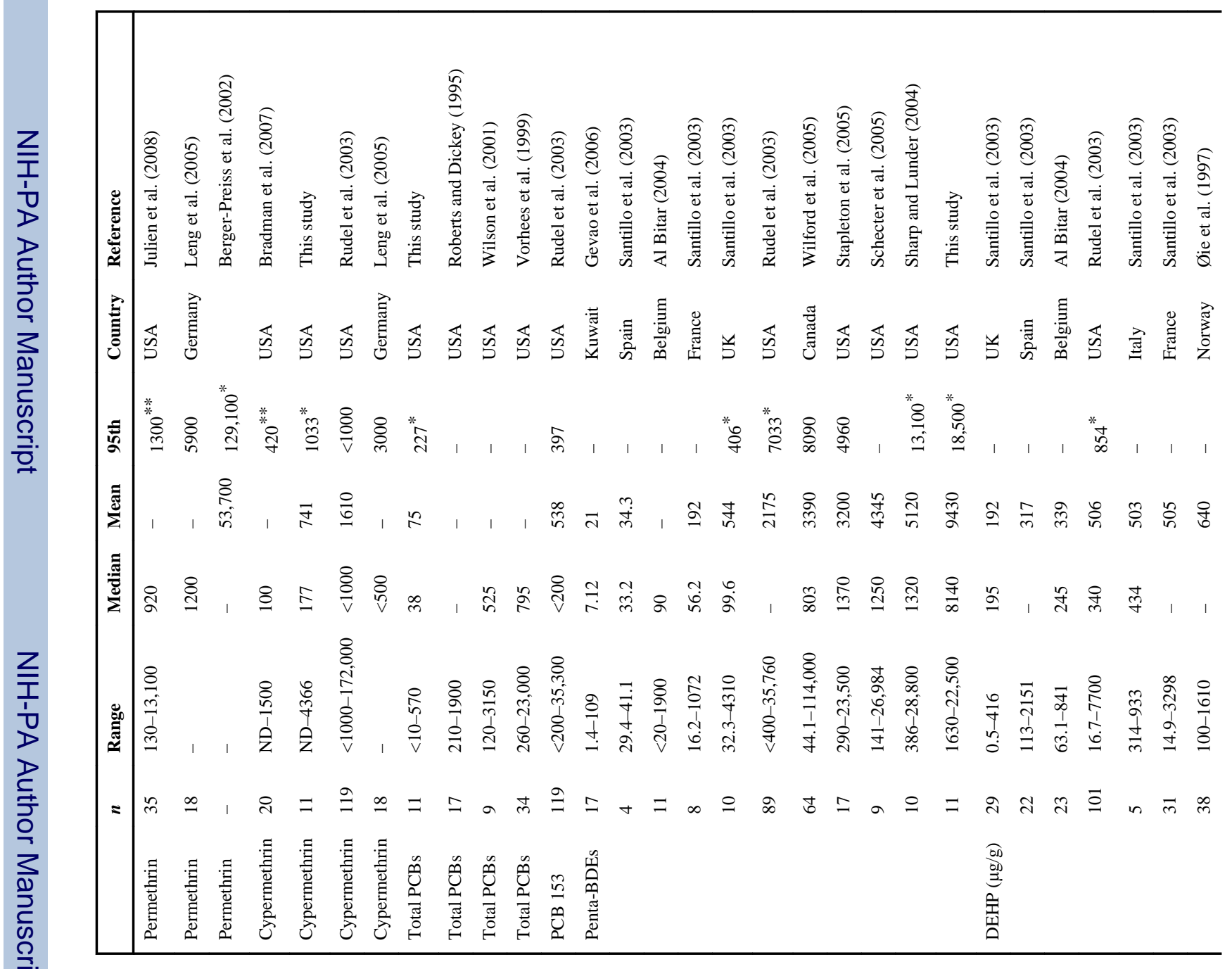




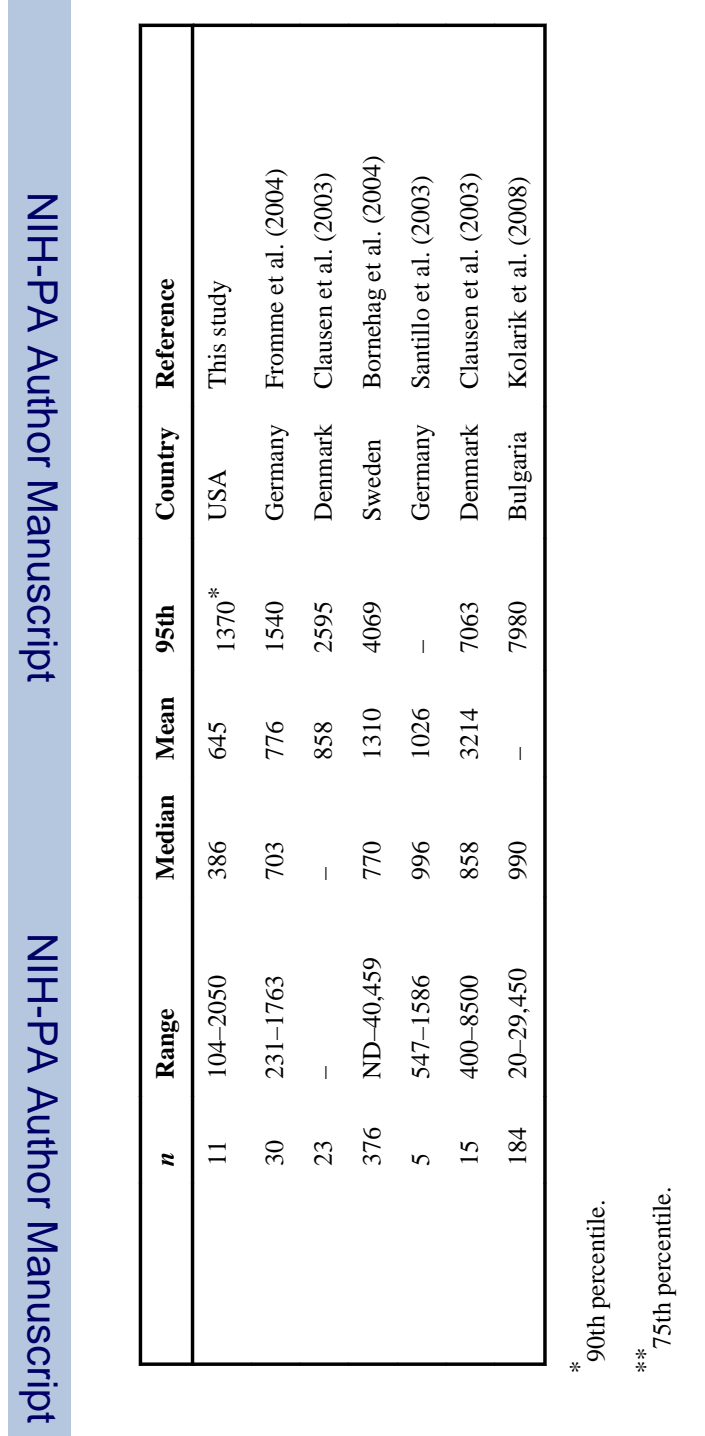

